\title{
ETOU electricity tariff for manufacturing load shifting strategy using ACO algorithm
}

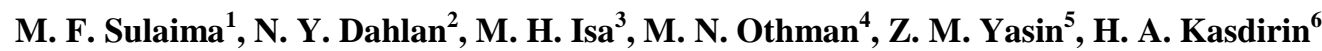 \\ ${ }_{1,2,5}$ Faculty of Electrical Engineering, Universiti Teknologi Mara (UiTM), Malaysia \\ ${ }^{1,3,4,6}$ University Teknikal Malaysia Melaka (UTeM), Malaysia
}

\begin{tabular}{l}
\hline \hline Article Info \\
\hline Article history: \\
Received Sep 30, 2018 \\
Revised Nov 23, 2018 \\
Accepted Dec 29, 2018 \\
\hline Keywords: \\
Ant Colony Optimization \\
(ACO) \\
Demand Side Management \\
(DSM) \\
Enhance time of use (ETOU) \\
Load profile \\
Load shifting \\
\hline
\end{tabular}

\begin{abstract}
This paper presents load shifting strategy for cost reduction on manufacturing electricity demand side, by which a real test load profile had been used to prove the concept. Superior bio-inspired algorithm, Ant Colony Optimization (ACO) had been implemented to optimize the upright load profile of load shifting strategy in the Malaysia Enhance Time of Use (ETOU) tariff condition. Subsequently, significant simulation results of operation profit gain through 24 hours electricity consumption had been analyzed properly. The proposed method had shown reduction of approximately $6 \%$ of the electricity cost at peak and mid peak zones, when $20 \%, 40 \%, 60 \%, 80 \%$ and $100 \%$ load shifting weightages were applied to the identified $10 \%$ controlled loads consequently. It is hoped that the finding of this study can help poise the manufacturers to switch to ETOU tariff as well as support the national Demand Side Management (DSM) program.
\end{abstract}

Copyright (C) 2019 Institute of Advanced Engineering and Science. All rights reserved.

\section{Corresponding Author:}

M. F. Sulaima,

Faculty of Electrical Engineering,

Universiti Teknologi Mara (UiTM), Malaysia

Email: fani@utem.edu.my

\section{INTRODUCTION}

Electricity energy cost has been considered as one of the revenue items with regards to business operation overheads such as in manufacturing operation. The undefined strategies of electricity tariff registration in regulated market such in Malaysia environment will continue to reduce profit margin; at the same time becoming insufficient for the energy management performance. Despite the introduction of new tariff structure in accordance with Enhance Time of Use (ETOU) tariff in Malaysia, reports state that tariff modality does not met their energy load profile that demand side consumers are reluctant to join the program. Even though the ETOU has been in market for quite a while, there is not enough consumers joining the program, less than $1 \%$ as recorded by Malaysia Energy Commission in [1]. The second reason of the introduction of the ETOU was related to the increase of the price rate of the electricity tariff under Incentive Based Regulation (IBR) regime that has been implemented since 2014 [2, 3].

With regards to the study related to ETOU tariff, several studies have been given priority to date. Conventional manual load shifting to industrial and commercial type of consumers in order to mitigate the electricity cost has been proposed in $[4,5]$. However, the studies did not propose any related solution toward implementation of optimization algorithm, while the formulation of the optimal ETOU cost is only based on three related zones. As in [6], the only reference presents six segmentation ETOU optimization by using Evolutionary Algorithm (EA). This algorithm based formulation that reflects ETOU rate study has been proposed for commercial consumer's load profile for comparison with the conventional flat tariff cost. Meanwhile, the tariff of OPTR has proven that moving the appropriate loads to the significant price rate time segments produces good results of electricity cost reduction. However, the proposed formulation is too open 
for the algorithm to perform, as the results it produced was had different desired load curve after simulation. The impact to the consumers is that, they must change their system operation and time arrangement significantly in order to achieve cost saving.

In general view, the studies of the Time of Use (TOU) have been presented in many ways and it was also depending on the electricity market but with same focused to optimize the utilization of TOU consumers' tariff. As example in [7], Iteration Particle Swarm Optimization (IPSO) was introduced to optimize the contract capacity on monthly data basis. TOU time frame had been analyzed to reflect the cost reduction of industrial consumers, while considering several factors in determining the optimal solution of the proposed algorithm. Consequently, sustainable program in the manufacturing process had been continued for overall optimal load scheduling by using Binary Particle Swarm Optimization (BPSO) technique. Close scheduling for optimal solution for the controllable load was discussed by the authors. The technique to formulate and define the efficient cost for the manufacturer revenue has been proposed in [8]. In conjunction to swarm base algorithm performance and load scheduling technique, the Evolutionary Algorithm (EA) optimization technique was introduced to deal with load shifting, specifically for standard machineries in residential, commercial and industrial consumers, as reported in [9]. Significant related study on evolutionary techniques has been continued by [10] by introducing Evolutionary Integer Genetic Algorithm (EIGA). The proposed technique was used to analyze the desired load curve for both consumers and providers, while promoting cost saving under the new tariff of Time of Day (TOD). Unfortunately, the TOD is only suitable for deregulated electricity market, since the development of the proposed technique requires days ahead of load forecasting and Real-Time Pricing (RTP). Meanwhile, optimization on specific system such as water heater and heat pump relative to TOU pricing has been reviewed in [11] and [12], respectively. In the studies, BPSO was applied in a controller to shift the schedule of water heater, including comparison of GA and PSO performance to find the optimal cost for heat pump and thermal storage scheduling. Recently, the Smart Grid (SG) system has been the focus in various aspects of research, including load shifting and implementation of optimization algorithm. Multi-objective optimal solution for residential consumers significant to SG environment for cost reduction and home appliance time delay minimization have been addressed in [13] and [14], while $\mathrm{CO}_{2}$ reduction, generation cost and consumers cost have been presented in [15]. Close reference with regard to the implementation of ACO to the load scheduling has been reported in [16]. Appropriate technique on how smart grid household equipment system should be scheduled in order to reduce the electricity cost has been proposed as well. However, the study only focus on residential consumers, and not highlight the issues for commercial and industrial consumers that very different in terms of the machineries and equipment operation. The study also was proposed for the deregulated market that was different to the regulated electricity market as in Malaysia energy industry practice.

Therefore, in this study, a novel mechanism is proposed in order to produce reference load curve by specific industrial ETOU consumers, as well as providing better technique of load shifting by using bioinspired algorithm, which is Ant Colony Optimization (ACO). The proposed technique aims to minimize electricity consumption cost for controlled loads in manufacturing daily operation, as the appropriate load profile will be able to upsurge in order to communicate to the price rate of each ETOU time segmentation. The investigation was to compare the test result of flat tariff E1 to ETOU E1 for the industrial load profile only. The real test baseline load profile was taken from an electronic manufacturing in southern Peninsular Malaysia. By this way, the demand side management program proposed by government can be optimized while increasing manufacturer profit simultaneously.

The rest of this paper is structured as follows. Section 2 briefly optimal ETOU load shifting formulation and ACO algorithm implementation to reflect the objective of the paper. Section 3 presents case study and the results of the study, while Section 4 discusses the analyses on the data results, and Section 5 presents the conclusion for the study.

\section{FORMULATION AND ALGORITHM IMPLEMENTATION}

Since the ETOU formulation is expressed in pricing unit where the objective function of the simulation is to optimize ETOU load curve, the general of ETOU electricity energy (RM/kWh) cost saving has been written as (1):

$$
\mathrm{ETOU}_{\text {cost }}^{\text {optimal }}=\Delta \mathrm{ETOU}_{\mathrm{eCost}}
$$

$\triangle \mathrm{ETOU}_{\mathrm{eCost}}$, is the electricity cost of desired load curve after load shifting is applied, which reflects six-time segmentation price base, as presented in (2) accordingly. 


$$
\begin{aligned}
& \Delta \mathrm{ETOU}_{\mathrm{eCost}}=\left(\sum_{\mathrm{t}}^{\mathrm{N}=10} \Delta \mathrm{P}_{\mathrm{op}} \times \mathrm{TP}_{\mathrm{op}}\right)+\left(\sum_{\mathrm{t}}^{\mathrm{N}=3} \Delta \mathrm{P}_{\mathrm{mp1}} \times \mathrm{TP}_{\mathrm{mp}}\right)+\left(\sum_{\mathrm{t}}^{\mathrm{N}=1} \Delta \mathrm{P}_{\mathrm{p} 1} \times \mathrm{TP}_{\mathrm{p}}\right)+\left(\sum_{\mathrm{t}}^{\mathrm{N}=2} \Delta \mathrm{P}_{\mathrm{mp} 2} \times \mathrm{TP}_{\mathrm{mp}}\right) \\
& +\left(\sum_{\mathrm{t}}^{\mathrm{N}=3} \Delta \mathrm{P}_{\mathrm{p} 2} \times \mathrm{TP}_{\mathrm{p}}\right)+\left(\sum_{\mathrm{t}}^{\mathrm{N}=5} \Delta \mathrm{P}_{\mathrm{mp} 3} \times \mathrm{TP}_{\mathrm{mp}}\right)
\end{aligned}
$$

where; $\Delta \mathrm{P}_{\text {op }}=$ changing of off peak desired load curve with changing of time, $\mathrm{N}=10$;

$\Delta \mathrm{P}_{\mathrm{mp1}}, \Delta \mathrm{P}_{\mathrm{mp} 2}, \Delta \mathrm{P}_{\mathrm{mp} 3}=$ changing of mid peak desired load curve with different time change, $\mathrm{N}=3, \mathrm{~N}=2$ and $\mathrm{N}=5$, respectively;

$\Delta \mathrm{P}_{\mathrm{p} 1}, \Delta \mathrm{P}_{\mathrm{p} 2}=$ changing of peak desired load curve at time changing $\mathrm{N}=1$ and $\mathrm{N}=3$ separately;

$\mathrm{TP}_{\mathrm{op}}=$ utility ETOU tariff price for off peak time zone;

$\mathrm{TP}_{\mathrm{mp}}=$ utility ETOU tariff price for mid peak time zone;

$\mathrm{TP}_{\mathrm{p}}=$ utility ETOU tariff price for peak time zone;

Thus, the general expression of total solution of Load Shifting (LS) strategies at six-time segmentation profile is written as in (3).

$$
\Delta \mathrm{P}_{\mathrm{OP}, \mathrm{MP} 1, \mathrm{P} 1, \mathrm{MP} 2, \mathrm{P} 2, \mathrm{MP} 3}^{\mathrm{General}}=\sum_{\mathrm{ts}, \mathrm{i}}\left(\Delta \mathrm{P}_{\mathrm{ts}, \mathrm{i}}^{\mathrm{LS}} \times \mathrm{W}_{\mathrm{LS}}\right)
$$

$\Delta \mathrm{P}_{\mathrm{ts}, \mathrm{i}}^{\mathrm{LS}}$ is the changing amount of desired load based on LS strategy by DSM at random load $(i)$ in time segmentation $(t s)$. Accordingly, the lower bound and upper bound of random load setting selection $(i)$ have been set as (4).

$$
0.05<\mathrm{i}<0.10
$$

Meanwhile, $\mathrm{W}_{\mathrm{LS}}$ is the weightage of LS strategy to be implemented in every single load profile concurrently, which has already been set by manufacturer, depending on the controlled and uncontrolled load available in percentage at particular time segmentation. Apart from that, the constraints of the LS strategy to be good in performance have been decided to be splitted into two which are constraints for LS and energy consumption before and after. LS in the ETOU program will be performed at selected randomly six-time segmentations, compared to the previous formulation by [4] which proposed ETOU load shifting to be best from peak to mid peak time zone. However, in this investigation, especially for the simultaneous LS strategy application, the best way to put LS is after randomly generating all segments in profiles, followed by determining the highest topology of price to lowest one during each segmentation. The process of the LS in ETOU load profile has been conducted using (5), (6) and (7), respectively.

$$
\begin{aligned}
& \Delta \mathrm{P}_{\mathrm{ts}, i}^{\mathrm{LS}} \cong \Delta \mathrm{Z}_{\mathrm{ts}, \mathrm{i}}^{\text {shift }} \\
& \Delta \mathrm{Z}_{\mathrm{ts}, \mathrm{i}}^{\text {shift down }}=\left(\Delta \mathrm{Z}_{\mathrm{up}}^{\text {shift }}-\left(\left(\Delta \mathrm{Z}_{\mathrm{up}}^{\text {shift }}-\Delta \mathrm{Z}_{\mathrm{down}}^{\text {shift }}\right) \times \omega\right)\right) \\
& \Delta \mathrm{Z}_{\mathrm{ts}, \mathrm{i}}^{\text {shift up }}=\left(\Delta \mathrm{Z}_{\text {up }}^{\text {shift }}-\left(\left(\Delta \mathrm{Z}_{\mathrm{up}}^{\text {shift }}+\Delta \mathrm{Z}_{\mathrm{down}}^{\text {shift }}\right) \times \omega\right)\right)
\end{aligned}
$$

where; $\Delta Z_{\mathrm{down}}^{\text {shift }}=$ changing of load decrease at certain time segmentation ( $\left.t s\right)$ for the load, $i$;

$\Delta Z_{\text {up }}^{\text {shift }}=$ changing of load increase at certain time segmentation ( $t s$ ) for the load, $i$

$\omega=$ the random weightage of load decrease and increase at lower bound and upper bound load setting as (4).

Meanwhile, total energy before and after of the optimization throughout the process of demand side strategies should not be more than $\pm 5 \%$. (8) describes the constraints of six segmentation for total energy before and after optimization accordingly.

$$
\sum \mathrm{E}_{\mathrm{T}} \cong \sum \mathrm{E}_{\mathrm{T}}^{\prime}
$$

In this study, the Ant Colony Optimization (ACO) has been implemented as the driver to find the optimum solution. Inspired by an ant colony foraging behavior, ACO uses the element of ant attribute to find the optimal path to the food source. In natural environment, pheromone is the communication channel for the ants to move around in finding possible food source through signal paths. Depositing pheromone establishes the communication between ants, where the stronger the pheromone, the longer the path. By the process of mimicking, the ant in ACO represents possible solution that consists of a set of nodes that have been visited by the ant in the line so far. Hence, when the next ants want to choose the nodes, these ants will possibly 
select the ones with highest level of pheromone. This situation contributes to the convergence of the optimal solution. Normally, ACO algorithm is developed in two importance parts, which are the processes of generating the ants, and updating pheromone. In part 1, the ACO process consists of generating a new set of ants in each iteration according to the desired nodes. The probability of an ant to select a certain node can be expressed using (9) accordingly.

$$
\mathrm{p}\left(\mathrm{a}_{\mathrm{ij}} \mid \mathrm{S}_{\mathrm{p}}\right)=\frac{\mathrm{r}_{\mathrm{ij}}^{\alpha} \eta_{\mathrm{ij}}^{\beta}}{\sum \mathrm{r}_{\mathrm{ij}}^{\alpha} \eta_{\mathrm{ij}}^{\beta}}
$$

where; $p\left(a_{i j} \mid S_{p}\right)=$ the probability of limit $a_{i j}$ will be chosen in line to the partial solution $S_{p}$

$\mathrm{a}_{\mathrm{ij}}=$ the limit from node $\mathrm{i}$ to node $\mathrm{j}$

$\mathrm{r}_{\mathrm{ij}}=$ the pheromone values at $\mathrm{a}_{\mathrm{ij}}$

$\eta_{i j}=$ an heuristic value, typically the inverse of the cost of going through $a_{i j}$

$\alpha=$ the pheromone importance factor

$\beta=$ the heuristic importance factor

Now, once the ant has evaluated its solution and calculating its fitness value, the value will be used in the following part 2, which is updating the pheromone process. This is where the level of deposited pheromone is identified. The increase of the pheromone value in trail as the ant deposits will strongly limit the connecting nodes it has used. In conjunction to that, there is possibility of decreasing of the pheromone level as well; the process is called evaporation. (10) and (11) illustrate the updating process of pheromone evaporation and reinforcement, respectively.

$$
r_{i j}=(1-\rho) * r_{i j}
$$

where; $\mathrm{r}_{\mathrm{ij}}=$ pheromone value at the limit from $i$ to $j$

$\rho=$ pheromone evaporation factor

$$
\mathrm{r}_{\mathrm{ij}}=\mathrm{r}_{\mathrm{ij}}+\sum \Delta \mathrm{r}_{\mathrm{ij}}
$$

where; $r_{i j}=$ pheromone value at the limit from $i$ to $j$

$\sum \Delta \mathrm{r}_{\mathrm{ij}}=$ pheromone to be added to the trail by an ant, which depends on the length/cost of the path taken by the ants.

Various attempts have been made by researchers to find the best solution, especially in engineering work. The steps for the ACO algorithm that has been applied in this study are as follows:

Step-1: Initialization of ants by setting $\alpha=1, \beta=0$ for Equation (9) and $\rho=0.3$ for (10), as referred from [17-19]. The ants represent a set of possible initial load profile to determine single 24-hour of change in each load of cost of electricity, called as nodes. The fitness values will be used for update of gathering more ants to proceed to the next step.

Step-2: Formulating the constraints and determining the cost. The updated pheromone values will be used to engage in the formulation of optimal ETOU pricing and the Load Shifting (LS) strategy as in (2), (5)-(7), respectively. The update of total load pricing in six-time segmentation will be used as the best Cost value in ACO process part 1, then to proceed to find the updated ants pheromone in part 2.

Step-3: The best total energy cost for all segmentations is determined by best Cost value during pheromone update, while the best ants to symbolize optimal load profile is created concurrently. Again, (10) and (11) are applied in this step.

Step-4: When the criterion for the best Cost has been fulfilled, the significant value of Cost is decided to be the convergence value to fulfill the set of constraints as well. If not, the list of new possible optimum setting of ants will take part, which means going through the process all over again.

\section{RESULTS AND ANALYSIS}

In this section, the case study and the load profile after simulation will be presented accordingly. In order to prove the effectiveness of the formulation and efficiency of the proposed algorithm, tests had been conducted by load profile of manufacturing. A one-year profile had been collected, which was then averaged into 1-day load profile within 24 hours. Figure 1 shows a part of the weekly profile as the reference for the readers. Data of electricity energy profile had been measured through energy logger (PEL103) of Chauvin Arnoux model at busbar of $11 \mathrm{kV}$ substation. 


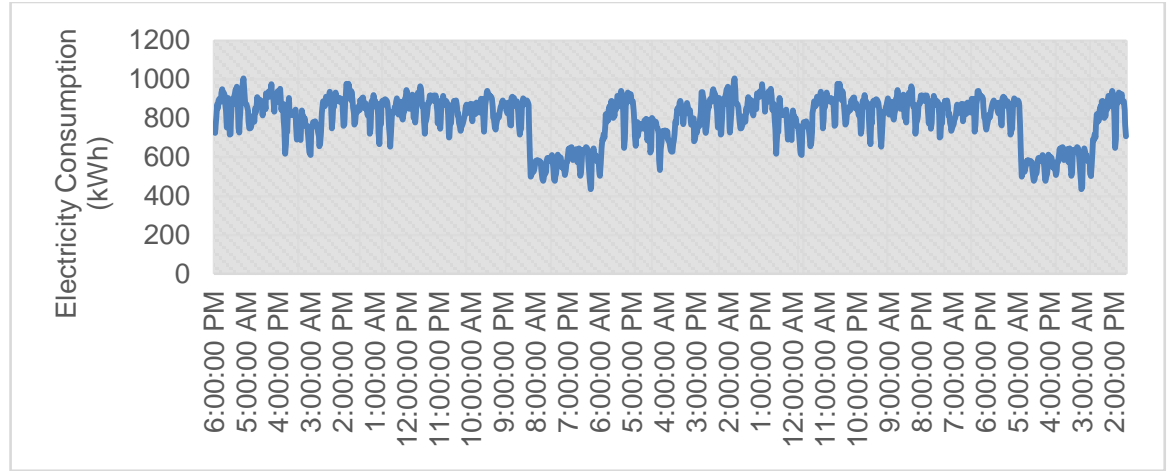

Figure 1. Two-week electricity consumption profile of manufacturing

\subsection{Case study}

For the analysis of the results by percentage of the load shifting adjustment, the arrangement of the cases for study had been set as follows:

Case 1: baseline of the existing E1 flat tariff rate

Case 2: E1 ETOU tariff rate without any LS and optimization

Case 3: E1 ETOU tariff rate by using $20 \%$ of the LS and ACO algorithm

Case 4: E1 ETOU tariff rate by using $40 \%$ of the LS and ACO algorithm

Case 5: E1 ETOU tariff rate by using $60 \%$ of the LS and ACO algorithm

Case 6: E1 ETOU tariff rate by using $80 \%$ of the LS and ACO algorithm

Case 7: E1 ETOU tariff rate by using $100 \%$ of the LS and ACO algorithm

Note that the controlled load to be adjusted was only available at $10 \%$, which had been identified during the detailed energy audit work at site. Hence, adjustment of the load shifting weightage had been set from $20 \%$ to $100 \%$ within the limitation of $10 \%$ controlled load only. In Figure 2, the load apportioning for the most electricity consumption per system by end user is presented accordingly. The identified adjusted controlled load of $10 \%$ to be shifted was the Etching process system. The rearrangement of the workers schedule was significant to the machine operational time table congruently. Since the base load average was $10 \%$ to $11 \%$, the control able load was decided to be the rest of that, which was $10 \%$. Analysis on the issue of the tariff transform into ETOU E1 type based on the seven cases will be explained in the next sub section accordingly.

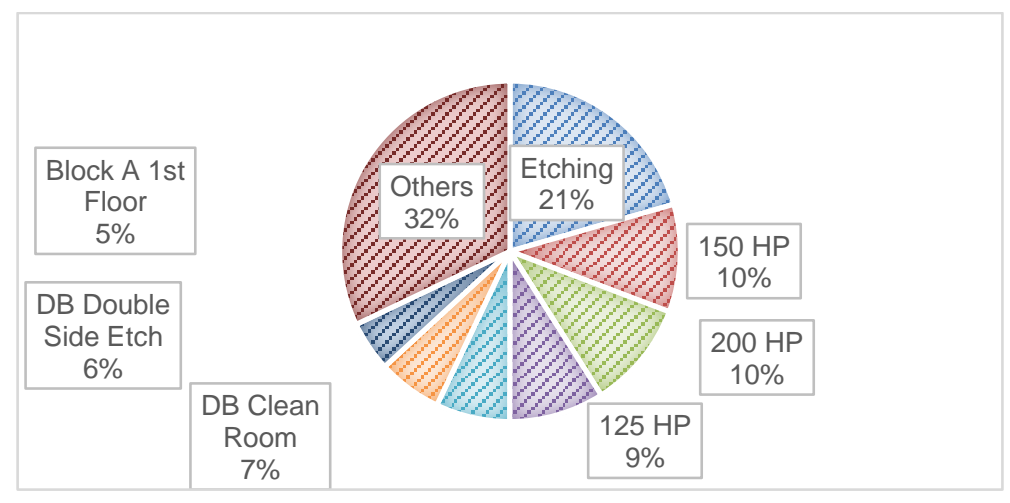

Figure 2. Load apportioning of manufacturing

\subsection{Analysis of results data}

The comparison of load profile management for all cases is presented in Figure 3. It can be observed that the generated load profiles in Case 3 until Case 7 were slightly different, compared to Case 2 which followed profile of baseline in Case 1. In terms of movement of the ants' load in the environment of 24-hour profile, the dedicated movement was presented by off peak zones (22:00pm to 8:00am) for all cases simultaneously. Case 7 was noticed to be more practical in reducing the load at peak zones and mid peak zones, while increasing the load at off peak zones accordingly. The top electricity demand for most cases 
were above $1100 \mathrm{~kW}$ at $4: 00 \mathrm{am}$ to $5: 00 \mathrm{am}$ but had recorded below $700 \mathrm{~kW}$ at mid peak zones $(18: 00 \mathrm{pm}$ to 19:00pm) during the rest time of the staff in manufacturing. In this study, without considering the changing of workers rest time and shift time, the optimization method has been in accordance to follow the existing schedule of manufacturing operation schedule. Therefore, the up and down of load profile after optimization was not much different when it was associated to the baseline as in Case 1.

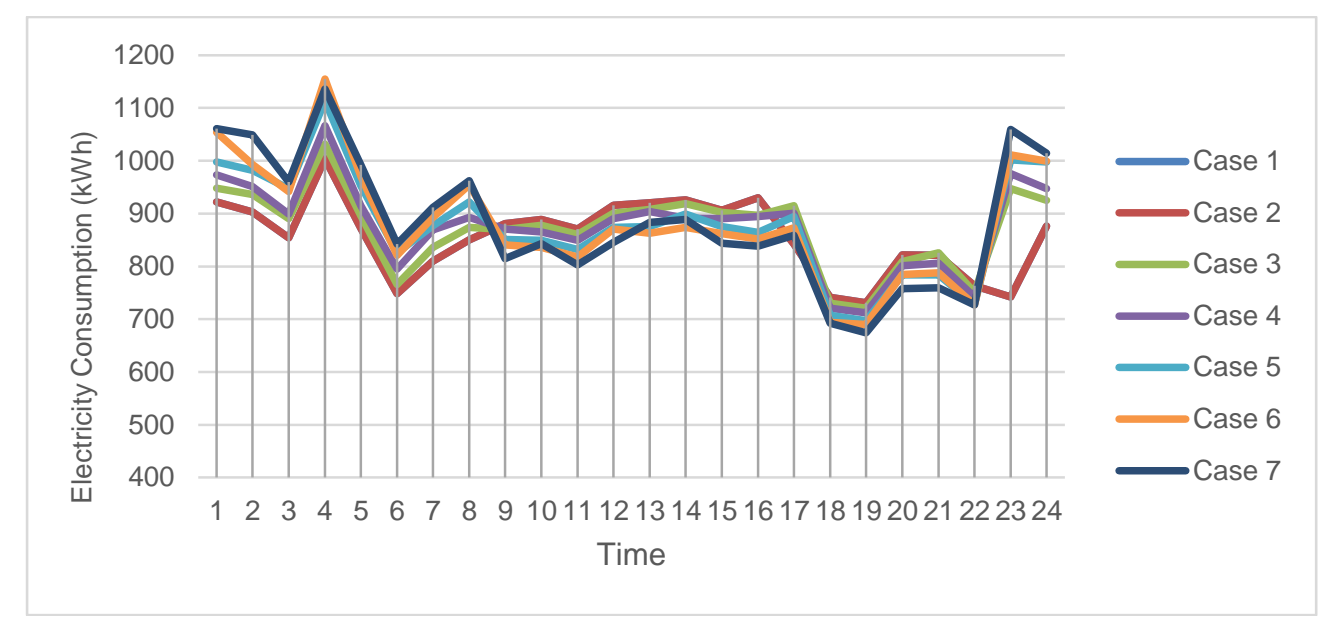

Figure 3. Load profile for all cases

Meanwhile, the energy cost of all cases after simulation are illustrated in Figure 4. Case 1 represents the existing flat tariff rate E1, and had the highest cost of electricity energy recorded of RM 6,921.98. Without any optimization method and demand strategy commitment (load profile as existing baseline), Case 2 had produced the lowest energy cost (RM 6,775.27). Here, cost saving was achieved approximately $1.2 \%$, up to $2.1 \%$, contributed by proposed method (Case 3 until Case 7) compared to baseline Case 1. It was perceived that the weightage set for the load shifting led to better performance at $100 \%$ adjustment, but the total cost of electricity energy had risen slightly than in Case 2. For the overall performance, ACO had performed well in mitigating the cost of energy while the initial electricity consumption profile of manufacturing already fulfilled the significant profile for ETOU tariff rate as well, as presented by Case 2 accordingly.

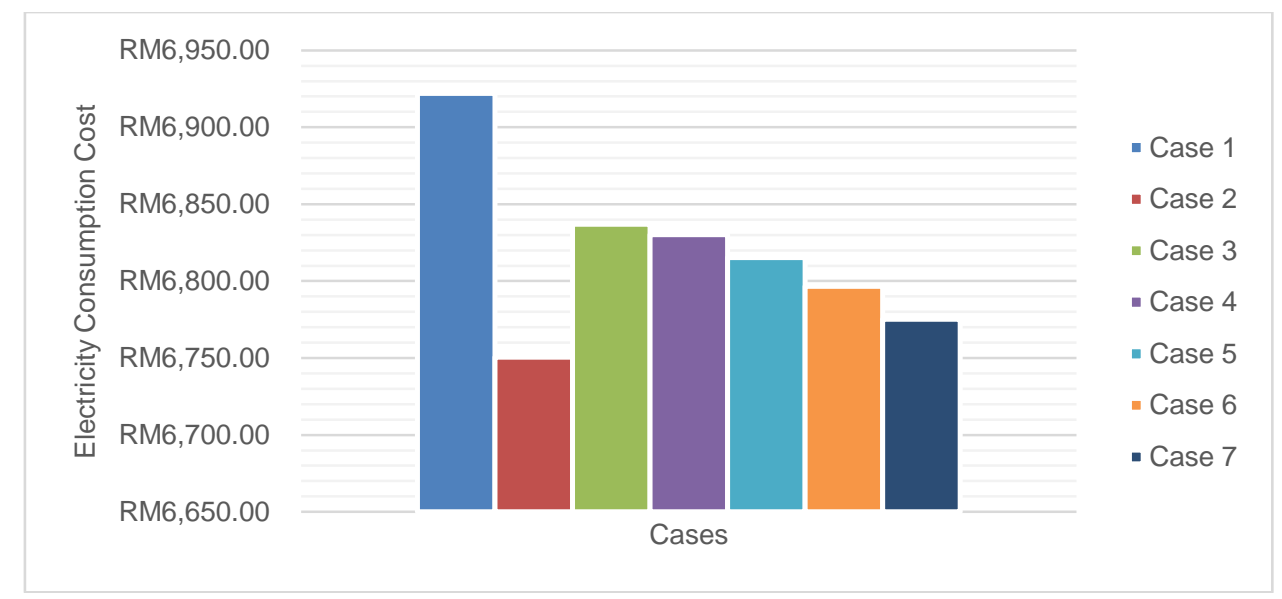

Figure 4. Electricity energy price for all cases

On the other hand, the performance of LS formulation with regard to the formulation with ACO algorithm is best to be investigated in single time segment as demonstrated in Figure 5. For overall 
distribution of the energy cost, off peak zone from 22:00pm to 8:00am was presented by time segmentation 1 (S1), which implied the highest cost for all cases, which increased gradually from Case 3 until Case 7 . The lowest cost price was time segmentation 3 (S3) due to peak hour account value which was set to 12:00pm only. Meanwhile, other segmentations, for instance S2 and S6 which represent mid peak zones, had produced electricity cost between RM 800.00 to RM 1,300.00 consistently. In conjunction to the overall electricity energy cost that belonged to Case 1 as the lowest, detailed investigation proved that ACO algorithm implementation had contributed to significant reduction of peak and mid peak electricity price, as well as reducing the density of load in most peak hour's zones. The percentages of the reduction for the Case 3 until Case 7 in managing the critical peak load compared to Case 2 are illustrated in Figure 6. In Case 7, the reduction of the peak cost had been recorded up to 5.8\% while the mid peak cost decreased to $6.24 \%$ ominously. For all cases, the time segmentation at mid peak zones was noticed to contribute to more cost reduction compared to peak electricity energy cost. It was summarized that, E1 ETOU tariff with ACO algorithm performed better load shifting strategy in mitigating electricity cost at certain time segmentations, while helping to reduce overall cost, compared to baseline flat tariff $\mathrm{C} 1$.

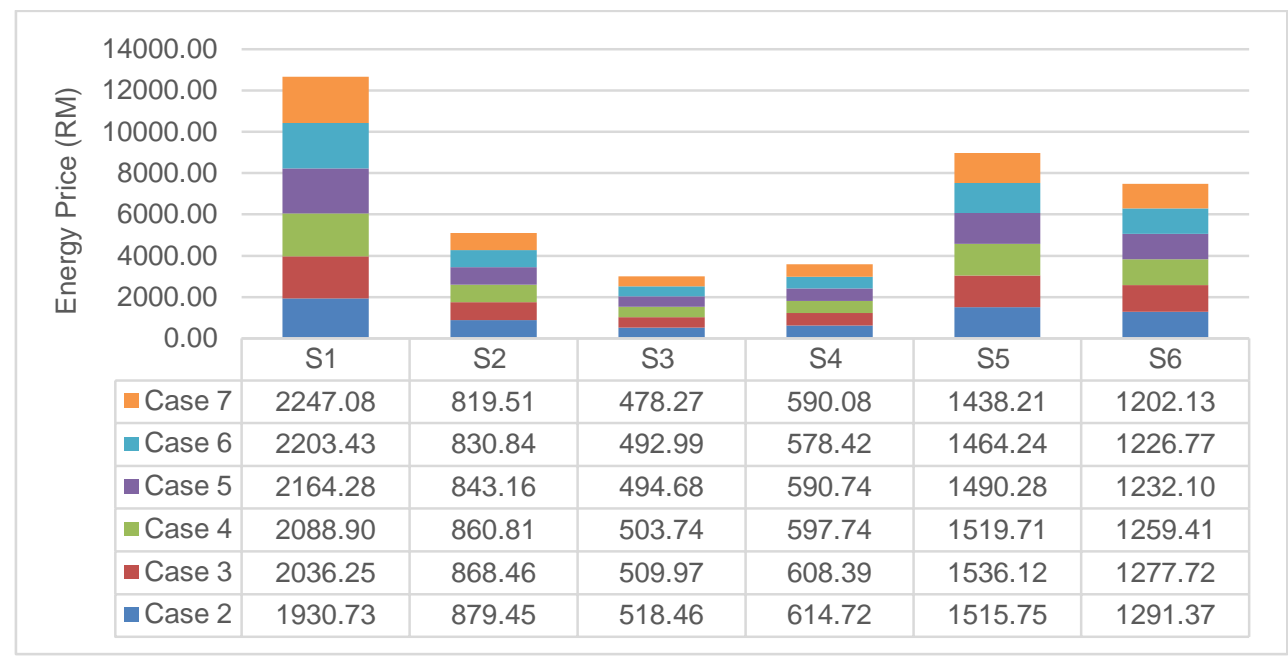

Figure 5. Electricity energy price for each segmentation in all cases

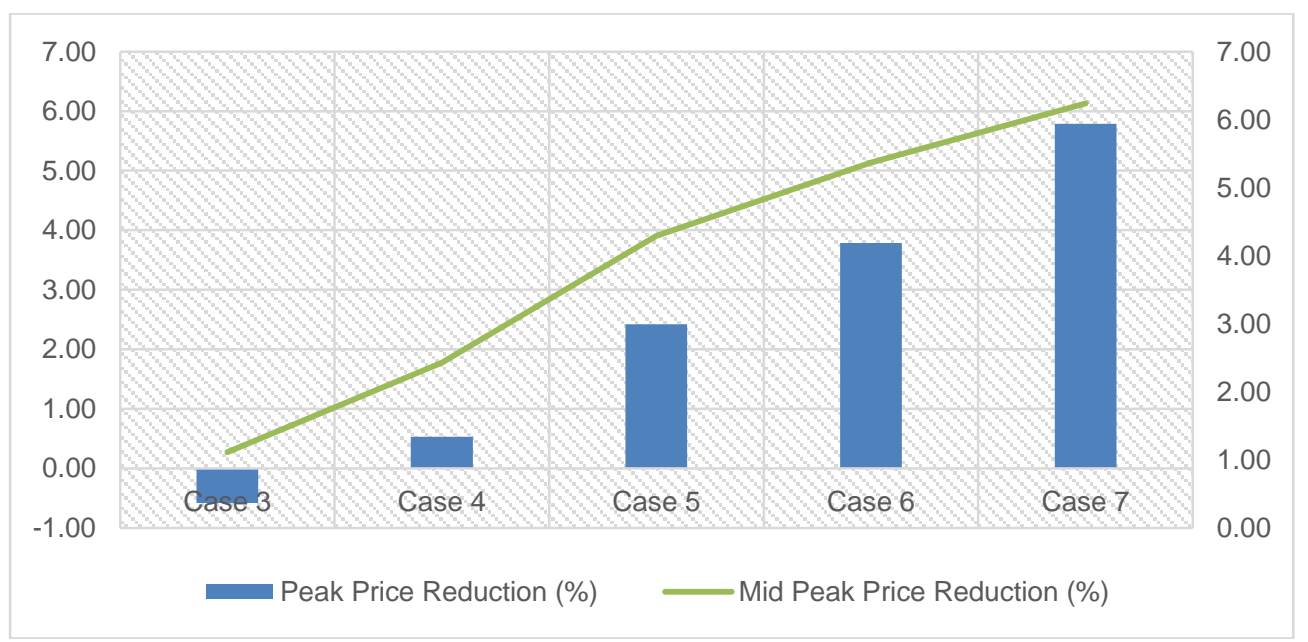

Figure 6. Price reduction for peak and mid peak zones

\section{DISCUSSION}

The obtained results show the ability of the proposed formulation and algorithm method to perform well in arranging the optimal operation of the controlled load. By referring to the Figure 7 as the comparison between baseline Case 1 to the Case 7 as 100\% load management was done, the 150HP's compressor that 
was determine to be adjustable load has been proposed to run after short break in night operation. As before, the operation of it was in normal working hours ( $8 \mathrm{am}$ to $17 \mathrm{pm}$ approximately 8hours of operation). This consideration was referred to the loads transfer procedure where the lowest loads has been considered to be fill up (during this time, all three compressor should be run simultaneously). Meanwhile the area of peak and mid-peak zones which ware high price rate has been reduced in order to balance the load arrangement before and after load shifting (150HP;s compressor should be shutdown to reflect workers rescheduling). The arrangement of the product and raw materials as well as workers schedule was suggested to be considered due to rescheduling of $150 \mathrm{HP}$ compressor operating hours. In the other hand, it was analyzed that the finding of this study was different to the previous references such in [4]. They consider only best percentage to be shift from dedicated time zones but the consideration of the controlled load for the specific consumers was not done. The controlled load to be involved in load shifting program was taken from the energy audit project that meticulously to the real operation consideration. The load patent that was produced by this study would be able to apply in real manufacturing operation such example that we have done for this study. Instead finding of the load curve that was presented by [6], the best produced load curve of this study was observed to be reliable for the application. Apart of that, the application of the ACO algorithm was the factor for the significant reduction of the electricity consumption cost; where the effectiveness of the search process such as the updating the Pheromone value to the Best cost had given the advantage. As the results, the accuracy and sustainability of the cost reduction during load management weightage adjustment from $10 \%$ to $100 \%$ was successful realized. By implementing different strategy when it was compared to [20] and [21] that consider only domestic consumers like residential buildings; the consideration and constraints that were attained by commercial and industrial buildings were risky when involving critical system operation especially in critical process input and output. Thus, as future discussion in this area of study at the same time reflect to our finding, we prepare several discussion questions for the future study:

a. Will best percentage of load management help the consumers to optimum the energy use as well as reduce the electricity consumption cost?

b. Are there any algorithms will help to classify the best DSM techniques in order to find the optimum load management consideration?

c. Is there any specific procedure for the ETOU tariff selection base on initial load profile and operation of the consumers' satisfaction?

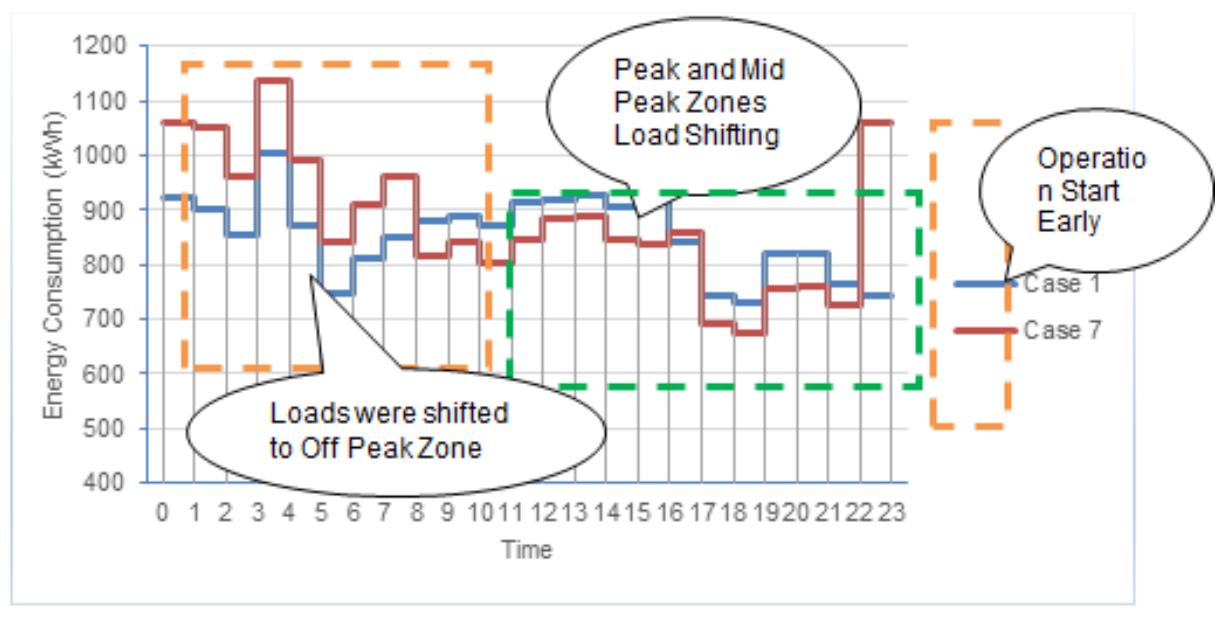

Figure 7. Comparison of the operation for baseline case 1 and best result of case 7

\section{CONCLUSION}

In this study, the load shifting strategy for the manufacturing electricity consumers in regards to the ETOU tariff pricing consideration has been done accordingly. The optimal formulation for Malaysia ETOU tariff come with load shifting setting has been embedded to the ACO algorithm that has helped to reduce peak demand as well as manage the controlled load. Meanwhile it has contributed to balance the need of energy consumption on demand side and generated power at provider side as well. $1 \%$ up to $6 \%$ energy cost reduction was achieved during mid peak time segmentations, while peak time segments contributed to reduction of cost approximately $0.5 \%$ up to $5 \%$ congruently. The significant analysis has proven that the 
adjustment of load profile in defining the ETOU tariff will benefit manufacturers in reducing operational cost, especially for those who are still using conventional flat tariff E1. For future works, several options will be considered for upgrading and comparing the optimization algorithms, while seeking to perform better optimization of ETOU tariff cost mitigation on the other DSM strategies as well. The dedicated questions on discussion section will be taken as the focus objectives for the next presentation.

\section{ACKNOWLEDGEMENTS}

The authors would like to thank Universiti Teknologi Mara (UiTM) and Universiti Teknikal Malaysia Melaka (UTeM) for all the support given.

\section{REFERENCES}

[1] S. Tenaga, "Laporan Tahunan Suruhanjaya Tenaga 2016," 2017.

[2] Tenaga Nasional Berhad, "Enhanced Time of Use (ETOU) Tariff Scheme," 2014.

[3] Energy Commission (Malaysia), "Enhanced Time of Use (ETOU) Tariff Scheme," 2014.

[4] N. A. M. Azman, M. P. Abdullah, M. Y. Hassan, D. M. Said, and F. Hussin, "Enhanced time of use electricity pricing for commercial customers in Malaysia," Pertanika J. Sci. Technol., vol. 25, pp. 285-294, 2017.

[5] N. Azrina, M. Azman, P. Abdullah, M. Y. Hassan, and D. M. Said, "Enhanced Time of Use Electricity Pricing for Industrial Customers in Malaysia," Indones. J. Electr. Eng. Comput. Sci., vol. 6, no. 1, pp. 155-160, 2017.

[6] M. F. Sulaima, N. Y. Dahlan, Z. M. Yasin, N. A. M. Asari, and Z. H. Bohari, "Optimum enhance time of use (ETOU) for demand side electricity pricing in regulated market: An implementation using evolutionary algorithm," Indones. J. Electr. Eng. Comput. Sci., vol. 8, no. 1, 2017.

[7] T. Y. Lee and C. L. Chen, "Iteration particle swarm optimization for contract capacities selection of time-of-use rates industrial customers," Energy Convers. Manag., vol. 48, no. 4, pp. 1120-1131, 2007.

[8] Y. Wang and L. Li, "Time-of-use based electricity demand response for sustainable manufacturing systems," Energy, vol. 63, pp. 233-244, 2013.

[9] T. Logenthiran, D. Srinivasan, and T. Z. Shun, "Demand side management in smart grid using heuristic optimization," IEEE Trans. Smart Grid, vol. 3, no. 3, pp. 1244-1252, 2012.

[10] N. Kinhekar, N. P. Padhy, and H. O. Gupta, "Multiobjective demand side management solutions for utilities with peak demand deficit," Int. J. Electr. Power Energy Syst., vol. 55, pp. 612-619, 2014.

[11] A. Sepulveda, L. Paull, W. G. Morsi, H. Li, C. P. Diduch, and L. Chang, "A novel demand side management program using water heaters and particle swarm optimization," in IEEE Electrical Power \& Energy Conference, 2010, pp. $1-5$.

[12] H. Molavi and M. M. Ardehali, "Utility demand response operation considering day-of-use tariff and optimal operation of thermal energy storage system for an industrial building based on particle swarm optimization algorithm," Energy Build., vol. 127, pp. 920-929, 2016.

[13] K. Muralitharan, R. Sakthivel, and Y. Shi, "Multiobjective optimization technique for demand side management with load balancing approach in smart grid," Neurocomputing, vol. 177, pp. 110-119, 2016.

[14] C. Li, X. Yu, W. Yu, G. Chen, and J. Wang, "Efficient Computation for Sparse Load Shifting in Demand Side Management," IEEE Trans. Smart Grid, pp. 1-12, 2016.

[15] G. Tsagarakis, R. Camilla Thomson, A. J. Collin, G. P. Harrison, A. E. Kiprakis, and S. McLaughlin, "Assessment of the Cost and Environmental Impact of Residential Demand-Side Management," IEEE Trans. Ind. Appl., vol. 52, no. 3, pp. 2486-2495, 2016.

[16] A. Silva, J. Marinheiro, H. L. Cardoso, and E. Oliveira, "Demand-Side Management in Power Grids: An Ant Colony Optimization Approach," in IEEE 18th International Conference on Computational Science and Engineering, 2015, pp. 300-306.

[17] P. Stodola, J. Mazal, and M. Podhorec, "Parameter Tuning for the Ant Colony Optimization Algorithm used in ISR systems," vol. 9, pp. 123-126, 2015.

[18] K. Shweta and A. Singh, "An Effect and Analysis of Parameter on Ant Colony Optimization for Solving Travelling Salesman Problem," Int. J. Comput. Sci. Mob. Comput., vol. 2, no. 11, pp. 222-229, 2013.

[19] K. Y. Wong, "Parameter tuning for ant colony optimization: A review," in International Conference on Computer and Communication Engineering, 2008, pp. 542-545.

[20] E. Shirazi and S. Jadid, "Cost Reduction and Peak Shaving Through Domestic Load Shifting and DERs," Energy, vol. 124, pp. 146-159, 2017.

[21] B. C. Ampimah, M. Sun, D. Han, and X. Wang, "Optimizing sheddable and shiftable residential electricity consumption by incentivized peak and off-peak credit function approach," Appl. Energy, vol. 210, pp. 1299-1309, 2018. 